\title{
A novel biphenyl urea compound, TPD7, stimulates apoptosis through modulating Fas signaling and Bcl-2 family proteins in cervical cancer
}

\author{
YINGZHUAN ZHAN, HAN ZHANG, BINGLING DAI, YANMIN ZHANG, \\ JIE ZHANG and LANGCHONG HE
}

School of Pharmacy, Health Science Center, Xi'an Jiaotong University, Xi'an, Shaanxi 710061, P.R. China

Received September 21, 2017; Accepted April 25, 2018

DOI: $10.3892 /$ or.2018.6472

\begin{abstract}
We recently reported that TPD7 suppressed tumor cell proliferation, and inhibited invasion, through the suppression of C-X-C chemokine receptor type 4 (CXCR4). In the present study, we investigated the anticancer effect of TPD7 on apoptosis and invasion of cervical cancer HeLa cells. Cell cycle analysis revealed that TPD7 decreased cyclin-dependent kinase (CDK)1 and cyclin D1 expression, and increased cyclin A expression, following S phase blockade. TPD7 induced chromatin condensation and significantly elevated the number of apoptotic cells, suggesting that its inhibitory effect on HeLa cells was due to the induction of cell cycle blockade and apoptosis. Mechanistically, TPD7 altered the extrinsic apoptosis pathway by upregulating Fas expression, and the intrinsic pathway by modulating Bcl-2 family proteins, $\mathrm{p} 53$, and $\mathrm{NF}-\kappa \mathrm{B}$ p65, leading to enhanced apoptosis. TPD7 inhibited HeLa cell invasion by downregulating the expression of matrix metalloproteinase (MMP)-9 and CXCR4 proteins. In vivo experiments revealed that TPD7 inhibited tumor growth in HeLa cell xenografted mice. These findings indicated that TPD7 may be a potential chemoprevention agent for the management of cervical carcinoma.
\end{abstract}

\section{Introduction}

Cervical cancer remains the second leading cause of cancerrelated deaths among women worldwide, accounting for 275,000 deaths annually (1). It is estimated that 12,990 new cases of cervical cancer were diagnosed in the United States in 2016, and 4120 people succumbed to the disease (2). Although cervical cancer death rates are decreasing among women in some developed countries, the incidence remains high among

Correspondence to: Professor Langchong He, School of Pharmacy, Health Science Center, Xi'an Jiaotong University, 76 Yanta West Street, Xi'an, Shaanxi 710061, P.R. China E-mail: helc@xjtu.edu.cn

Key words: cervical cancer, TPD7, apoptosis, Fas, Bcl-2
Southeast Asia, Central and Eastern Europe, the Caribbean, sub-Saharan Africa, and Latin America populations due to persistent human papillomavirus infections that lead to the occurrence of cancerous lesions (3-5).

The approaches currently used to treat cancer, such as radiation therapy, chemotherapy, gene therapy, or immune-based treatments, usually kill cancer cells by inducing apoptosis. Apoptosis is an intrinsic form of programmed cell death that occurs in response to various physiological and pathological processes. Apoptosis is identified by typical changes in cell morphology and biology, including cell shrinkage, nuclear chromatin condensation and DNA fragmentation $(6,7)$.

Apoptosis can be triggered via both the intrinsic (mitochondrial) and extrinsic (Fas receptor) pathways, with all signaling converging on key effectors that include caspase-3 or -7 (8). In the intrinsic apoptotic pathway, caspase activation is tightly linked to permeabilization of the outer mitochondrial membrane by pro-apoptotic members of the Bcl-2 family $(6,9)$. Cells typically die via apoptosis in a healthy organism. However, in tumor tissues, there is an insufficient number of apoptotic cells resulting in uncontrolled cell proliferation. For this reason, drugs that selectively trigger apoptosis of cancer cells by targeting the extrinsic pathway offer promise for cancer treatment.

Targeting the extrinsic pathway to trigger apoptosis in cancer cells is an attractive approach for cancer therapy since death receptors are a key factor for the cell death process $(7,10)$. Activation of the intrinsic pathway in cancer cells is another way to trigger apoptosis. For example, some chemotherapeutic agents, such as doxorubicin, cisplatin or paclitaxel, can enhance mitochondrial permeabilization by increasing the concentration of pro-apoptotic second messengers or by triggering perturbations of intermediary metabolism in an indirect fashion (6). However, cancer cells often develop resistance to these drugs during these types of therapies $(11,12)$. Thus, searching for new alternatives remains urgent in cancer therapy.

Taspine, a natural alkaloid that exists in many types of plants, was identified in our laboratory from Radix et Rhizoma Leonticis by using cell membrane chromatography. This compound exhibited inhibitory effects on some cancer cells (14-16). As one of the novel biphenyl urea taspine derivatives, TPD7 (N-(4'-acetyl-3',5,6-trimethoxybiphenyl- 
3-yl)-N'-[4-(3-morpholin-4-ylpropoxy)phenyl]urea) (13) (Fig. 1A) significantly inhibited the proliferation of different cancer cell lines. In the present study, we demonstrated that TPD7 effectively decreased the growth of HeLa cervical cancer cells. Mechanistically, we determined that TPD7 caused cell cycle blockade and triggered apoptosis in these cells.

\section{Materials and methods}

Animals and cell culture. The use of Balb/c mice for the purpose of this study was approved by the Animal Ethics Committee of Xi'an Jiaotong University (Permission no. XJTULAC2013-031). All experiments were conducted in accordance with the approved guidelines of the regional authorities according to Xi'an Jiaotong University animal care regulations. Female immunodeficient Balb/c mice (4-6 weeks of age) were obtained from the Shanghai Laboratory Animal Center of the Chinese Academy of Sciences and housed under aseptic and ventilated conditions.

The HeLa cervical cancer cell line, obtained from the Shanghai Institute of Cell Biology at the Chinese Academy of Sciences, was cultured in RPMI-1640 medium (Sigma-Aldrich; Merck KGaA, St. Louis, MO, USA) supplemented with $10 \%$ (v/v) fetal bovine serum (FBS; Hyclone Laboratories; GE Healthcare Life Sciences, Logan, UT, USA). Human primary endocervical epithelial cells were obtained from $\mathrm{CHI}$ Scientific, Ltd. (Wuxi, China), and maintained in DMEM/F12 medium (Sigma-Aldrich; Merck KGaA) supplemented with $10 \%$ (v/v) FBS (Hyclone Laboratories; GE Healthcare Life Sciences), EGF, insulin and hydrocortisone. All cell lines were incubated at $37^{\circ} \mathrm{C}$ in a $5 \% \mathrm{CO}_{2}$ incubator with saturated humidity. The cumulative culture length of HeLa cells was fewer than six months after resuscitation.

Cell viability assay. For the HeLa cell line, cells were seeded in a 96-well plate at a density of 4000 cells/well and treated with $1.56,3.13,6.25,12.5,25$ and $50 \mu \mathrm{mol} / 1$ TPD7 for 24, 48 and $72 \mathrm{~h}$. Then, $0.5 \mathrm{mg} / \mathrm{ml}$ 3-(4,5-dimethylthiazol-2-yl)-2,5-diphenyltetrazolium bromide (MTT) (Sigma-Aldrich; Merck $\mathrm{KGaA}$ ) solution was added to each well. After $4 \mathrm{~h}$ of incubation, the absorbance of each well was measured at $490 \mathrm{~nm}$ with a microplate reader (Bio-Rad Laboratories, Inc., Hercules, CA, USA). For human primary endocervical epithelial cells, cells were seeded in a 96-well plate at a density of 4000 cells/well and treated with 1.56, 3.13, 6.25, 12.5, 25 and 50 $\mu \mathrm{mol} / 1$ TPD7 for $48 \mathrm{~h}$. Then, an MTT assay was performed to evaluate the effect of TPD7 on cell viability.

Colony formation assay. HeLa cells were trypsinized and seeded in a 6-well plate at a density of 400 cells/well. After overnight adherence, cells were treated with 1 or $2 \mu \mathrm{mol} / 1$ TPD7 for 10-15 days. Cell numbers $>50$ were counted as colonies after staining with $0.2 \%$ crystal violet solution (Beijing Chemical Works, Beijing, China).

Cell cycle analysis. For the cell cycle analysis, HeLa cells were trypsinized and seeded in a 6-well plate at a density of $6 \times 10^{5}$ cells/well. After overnight adherence, the cells were incubated with 2,4 and $8 \mu \mathrm{mol} / 1$ TPD 7 for $48 \mathrm{~h}$. The cells were then harvested with trypsin/EDTA, resuspended and fixed overnight with ice-cold $70 \%$ ethanol at $4^{\circ} \mathrm{C}$. RNase and propidium iodide (PI) were then added and the mixture was incubated for $30 \mathrm{~min}$ away from light. Cell samples were then analyzed for the cell cycle distribution using a flow cytometer (BD Biosciences, Franklin Lakes, NJ, USA).

Hoechst staining assay. Hoechst staining was used to observe apoptotic changes in nuclear morphology. HeLa cells were cultured in a 6 -well plate at a density of $2 \times 10^{5}$ cells/well and then treated with 2, 4 and $8 \mu \mathrm{mol} / 1$ TPD7 for $48 \mathrm{~h}$. After incubation, the cells were washed three times with phosphatebuffered saline (PBS) and fixed with paraformaldehyde at $4^{\circ} \mathrm{C}$ for $30 \mathrm{~min}$. Cells were then washed with PBS and allowed to dry on the bottom of the well. Hoechst 33342 was added to each well and incubated at $37^{\circ} \mathrm{C}$ for $10 \mathrm{~min}$. The dye was then removed and cells were washed with PBS prior to observation of the cellular morphology under a microscope (Nikon Eclipse Ti-E; Nikon, Tokyo, Japan). The number of apoptotic cells was determined by assessing the percentage of cells displaying chromatin condensation compared to the total number of cells.

Analysis of apoptosis by flow cytometry. HeLa cells seeded in a 6-well plate at a density of $6 \times 10^{5}$ cells/well were incubated with 2, 4 and $8 \mu \mathrm{mol} / 1$ TPD7 for $48 \mathrm{~h}$, then trypsinized with trypsin-EDTA, centrifuged and suspended in PBS. Following double staining with Annexin V-FITC (5 $\mu \mathrm{l})$ and $20 \mu \mathrm{g} / \mathrm{ml}$ PI (10 $\mu \mathrm{l})$ for $15 \mathrm{~min}$ away from light, the samples were analyzed for apoptosis by flow cytometry.

Cell migration assays. To determine the effect of TPD7 on HeLa cell migration, wound healing and Millicell (EMD Millipore, Billerica, MA, USA) chamber assays were used. HeLa cells were seeded at $2 \times 10^{5}$ cells/well in a 12 -well plate and allowed to grow overnight up to $70 \%$ confluency in complete medium. Cells were then incubated in serum-free medium for $24 \mathrm{~h}$. Wounds were made by scratching the cell monolayers with a $10-100 \mu 1$ pipette tip. Wounded monolayers were washed several times with serum-free medium to remove floating cells and photographed under a microscope. Cells were then treated with 2, 4 and $8 \mu \mathrm{mol} / 1$ TPD7 for 48 and $72 \mathrm{~h}$ and the average distance the cells migrated into the scratched area was determined under an inverted microscope as an index of cell migration ability.

To conduct the chamber assay, HeLa cells suspended in culture medium were seeded at a density of $4 \times 10^{4}$ cells/well in an upper chamber $(8-\mu \mathrm{m}$ pore size) placed in a 12 -well plate. Vehicle- or TPD7-containing medium supplemented with $10 \%$ FBS was added to the upper chamber the following day. Medium supplemented with $30 \%$ FBS was added to the lower chamber as a chemoattractant. After $48 \mathrm{~h}$ of treatment, the cells on the upper surface of the chamber were carefully removed and migrating cells on the lower surface were fixed with $100 \%$ methanol and stained with $0.2 \%$ crystal violet (Beijing Chemical Works). Stained cells on the lower surface were visualized and images were captured in five microscopic fields that were selected randomly (magnification, x100).

Invasion assay. HeLa cells were seeded at a density of $4 \times 10^{4}$ cells/well in an upper Millicell chamber $(8-\mu \mathrm{m}$ pore size; EMD Millipore) coated with $100 \mu$ l Matrigel 
A<smiles>COc1cc(-c2ccc(/C(C)=N/O)c(OC)c2)ccc1NC(=O)Nc1ccc(OCCCN2CCOCC2)cc1</smiles>

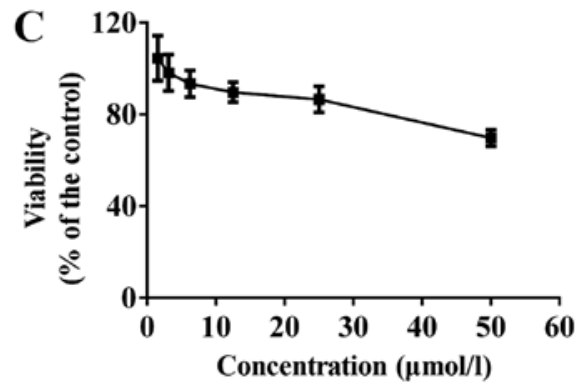

D

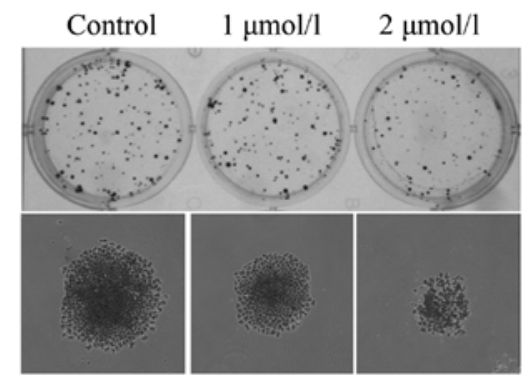

Figure 1. TPD7 suppresses the proliferation and colony formation of HeLa cells. (A) Chemical structure of TPD7. (B) HeLa cells were treated with 1.56, 3.13, $6.25,12.5,25$ and $50 \mu \mathrm{mol} / 1$ TPD7 for 24,48 and $72 \mathrm{~h} .{ }^{*} \mathrm{P}<0.05 ;{ }^{* *} \mathrm{P}<0.01$ compared with the control. (C) Human primary endocervical epithelial cells were treated with $1.56,3.13,6.25,12.5,25$ and $50 \mu \mathrm{mol} / 1$ TPD7 for 24,48 and $72 \mathrm{~h}$. (D) TPD7 suppressed the colony formation of HeLa cells. The upper image is of a single well of a 6-well plate photographed after staining with $0.2 \%$ crystal violet solution. The lower image is of a representative single colony. Quantitative data are presented as the means \pm SEM for triplicate experiments.

(Becton-Dickinson; BD Biosciences, San Jose, CA, USA) at a concentration of $1 \mathrm{mg} / \mathrm{ml}$, which was placed in a 12 -well plate. Vehicle- or TPD7-containing medium supplemented with $10 \%$ FBS was added to the upper chamber the following day. Medium supplemented with $30 \%$ FBS was added to the lower chamber as a chemoattractant. Following $48 \mathrm{~h}$ of treatment, the cells on the upper surface of the chamber were removed and invading cells were fixed with $100 \%$ methanol and stained with $0.2 \%$ crystal violet (Beijing Chemical Works), and images were captured in five randomly selected microscopic fields (magnification, x100).

Immunoblotting analysis. HeLa cells were seeded at a density of $6 \times 10^{5}$ cells/well in a 6 -well plate and incubated with 2, 4, and $8 \mu \mathrm{mol} / 1 \mathrm{TPD} 7$ for $48 \mathrm{~h}$. Cells were then washed with PBS to remove the medium and lysed with RIPA lysis buffer (Applygen Technologies, Inc., Beijing, China) supplemented with protease inhibitor cocktail tablets and phosphatase inhibitor cocktail tablets (Roche Diagnostics, Basel, Switzerland). The cell lysates were spinned at $12,000 \mathrm{x} \mathrm{g}$ at $4^{\circ} \mathrm{C}$ for $10 \mathrm{~min}$ and the supernatants were collected. Protein concentration in supernatants was assessed using a BCA protein quantification kit (Bio-Rad Laboratories, Inc.). An equal amount of proteins was separated by $10 \%$ SDS-PAGE, transferred to PVDF membranes (EMD Millipore). The membranes were then incubated with primary and secondary antibodies, respectively. The blots were detected using ECL reagents (Thermo Fisher Scientific, Inc.). The GAPDH antibody (1:1,000 dilution; cat. no. 10494-1-AP; ProteinTech Group, Inc., Chicago, IL, USA) was used as internal control. The primary antibodies including cyclin D1 (cat. no. 2978), CDK2 (cat. no. 2546), Apaf-1 (cat. no. 8969), Bak (cat. no. 6947), Bax (cat. no. 5023), Bcl-2 (cat. no. 4223), Bad (cat. no. 9239), Mcl-1 (cat. no. 94296), Fas (cat. no. 4233), cleaved caspase-3 (Asp175) (cat. no. 9664), cleaved PARP (cat. no. 5625) (all from Cell Signaling Technology, Danvers, MA, USA, 1:1,000 dilution before use), cyclin A2 (cat. no. 18202-1-AP), CDK1 (cat. no. 19532-1-AP), FADD (cat. no. 14906-1-AP) (all from ProteinTech Group, 1:1,000 dilution before use), p53 (cat. no. 1026-1), NF-кB p65 (cat. no. 1546-1), CXCR4 (cat. no. 3108-1), MMP-2 (cat. no. 1948-1), MMP-9 (cat. no. 1939-1) (all from Epitomics; Abcam Cambridge, MA, USA, 1:1,000 dilution before use) were detected in this assay.

Animal experiments. For acute toxicity assessment, Balb/c female mice were divided randomly into five groups of eight. Mice received a single dose of TPD7 at 100, 500, 1,000, 2,000 and $5,000 \mathrm{mg} / \mathrm{kg}$, while the control animals received equivalent volumes of solvent. General behavioral and body weight changes, hazardous symptoms and mortality were observed the next day and for 21 days.

For xenograft studies, female nude Balb/c mice at 4-6 weeks of age were implanted subcutaneously in the right flank with HeLa cells resuspended in 5\% saline. Mice were observed daily for the presence of palpable tumors. Tumor volumes (in $\mathrm{cm}^{3}$ ) were determined on alternate days by using a vernier caliper and the formula: (length $\mathrm{x}$ width ${ }^{2}$ )/2. Body weights were assessed daily to monitor overall health. Mice were divided randomly into four groups of eight when tumor volumes reached $\sim 0.1 \mathrm{~cm}^{3}$. In all studies, animals received either vehicle (equivalent volumes of solvent) or TPD7 daily at 50,100 , or $200 \mathrm{mg} / \mathrm{kg}$ for 21 days. For assessment of the effect of TPD7 treatment in HeLa xenograft-bearing mice, tumor tissues were excised from the injection site and weighed after mice were sacrificed. The percentage inhibition of tumor growth was calculated with the following formula: [(A - B)/A] $\mathrm{X} 100$, where $\mathrm{A}$ and $\mathrm{B}$ were the mean tumor weights of the control and treatment groups, respectively. 

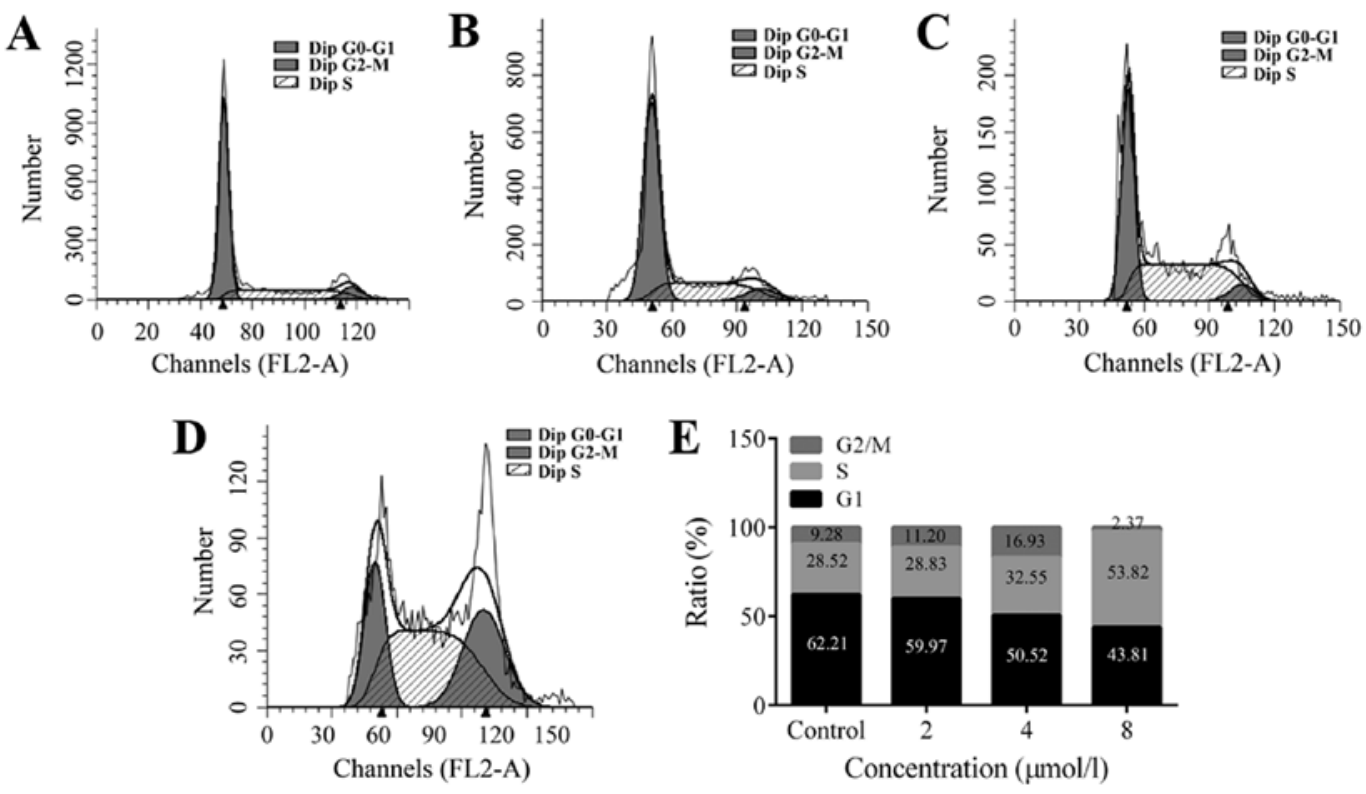

Figure 2. TPD7 arrests the cell cycle at the $\mathrm{S}$ phase. HeLa cells were treated with (A) vehicle (control), (B) 2 , (C) 4 , and (D) $8 \mu$ mol/1 TPD7 for 48 h, and then stained with propidium iodide for $30 \mathrm{~min}$, followed by flow cytometric analysis. (E) Percentages of the cells in the indicated phases of the cell cycle in the control and treatment groups.

Statistical analyses. Quantitative data are presented as the means \pm standard error of the mean (SEM). All data analyses were performed with the Prism software (GraphPad, Inc., La Jolla, CA, USA), and statistical comparisons were performed with SPSS 19.0 (IBM Corp., Armonk, NY, USA). ANOVA was used to determine statistical significance of the data compared with the control group. $\mathrm{P}<0.05$ was considered to indicate a statistically significant difference.

\section{Results}

TPD7 suppresses viability and colony formation of HeLa cells. An MTT assay was used to evaluate the effect of TPD7 on the proliferation of human cervical cancer HeLa cells. TPD7 exhibited significant inhibitory effects on HeLa cell proliferation in a dose- and time-dependent fashion (Fig. 1B). The $50 \%$ inhibitory concentration $\left(\mathrm{IC}_{50}\right)$ of $\mathrm{TPD} 7$ at $48 \mathrm{~h}$ was $9.95 \mu \mathrm{mol} / 1$, whereas the $\mathrm{IC}_{50}$ value of TPD7 to inhibit human primary endocervical epithelial cells at $48 \mathrm{~h}$ was higher than $50 \mu \mathrm{mol} / 1$ (Fig. 1B and C), suggesting that TPD7 was considerably less active in human primary endocervical epithelial cells. Concentrations lower than the $\mathrm{IC}_{50}$ value were considered less toxic, and were used in further studies. In addition, the $\mathrm{IC}_{50}$ value in HeLa cells was not significantly different between TPD7 at 48 and $72 \mathrm{~h}$ of treatment. Thus, 2,4 and $8 \mu \mathrm{mol} / \mathrm{l}$ of TPD7 at $48 \mathrm{~h}$ of treatment was adopted to investigate the anticancer potential of TPD7 on HeLa cells in subsequent mechanism studies.

The colony formation assay revealed that TPD7 treatment generated a significantly lower number of colonies compared with the vehicle (Fig. 1D). These results demonstrated that TPD7 exhibited potential anticancer properties in human cervical cancers in vitro.

TPD7 induces $S$ phase arrest in HeLa cells. To assess the mechanisms underlying the suppressive effects of TPD7 on
HeLa cell growth, we evaluated cell cycle progression after TPD7 treatment. Cells treated with TPD7 for $48 \mathrm{~h}$ displayed $\mathrm{S}$ phase arrest (Fig. 2). The percentages of cells in the $\mathrm{S}$ phase were $28.83,32.55$ and $58.82 \%$ following treatment with 2,4 and $8 \mu \mathrm{mol} / 1$ TPD7, respectively. Accordingly, the number of cells in the $\mathrm{G} 2 / \mathrm{M}$ phase decreased from 62.21 to $59.97,50.52$, and $43.81 \%$ with 2,4 and $8 \mu \mathrm{mol} / 1$ TPD7, respectively. These data indicated that TPD7 regulated the distribution of cells by blocking the cell cycle in the $\mathrm{S}$ phase.

TPD7 induces apoptosis of HeLa cells. Hoechst staining was used to determine nuclear morphological changes of cells exposed to various concentrations of TPD7. Treatment with 2, 4 and $8 \mu \mathrm{mol} / 1 \mathrm{TPD} 7$ for $48 \mathrm{~h}$ induced evident changes in nuclear morphology such as nuclear condensation or fragmentation (Fig. 3A).

Flow cytometric analysis was used to investigate the percentage of apoptotic cells induced by TPD7. The results revealed that, compared with the control, the percentage of apoptotic cells was elevated in the TPD7 treatment groups (Fig. 3B and C). Collectively, the results in Fig. 3 indicated that TPD7 could induce HeLa cell apoptosis.

TPD7 inhibits the migration and invasion of HeLa cells. Wound healing and chamber assays were used to determine the effects of TPD7 on HeLa cell mobility. For wound healing, confluent cell monolayers were scratched to form a wound and then cultured in medium with various concentrations of TPD7 $(2,4$ and $8 \mu \mathrm{mol} / \mathrm{l})$ for 48 or $72 \mathrm{~h}$. The movement of cells treated with TPD7 was much slower than the control cells (Fig. 4A).

The Millicell chamber assay was a second approach used to asceertain the inhibitory effect of TPD7 on HeLa cell mobility. This assay revealed that the cell number on the lower surface of the insert was decreased following $48 \mathrm{~h}$ of TPD7 treatment (Fig. 4B and C). Collectively, these results revealed that TPD7 impaired HeLa cell migration. 
A

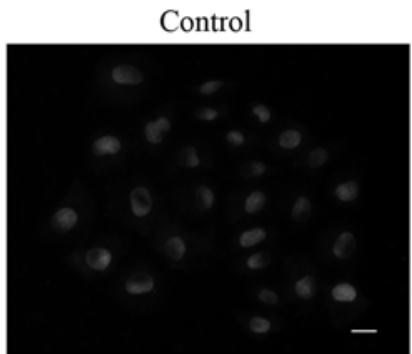

$2 \mu \mathrm{mol} / 1$

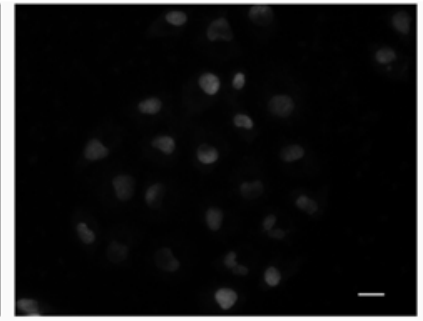

$4 \mu \mathrm{mol} / 1$

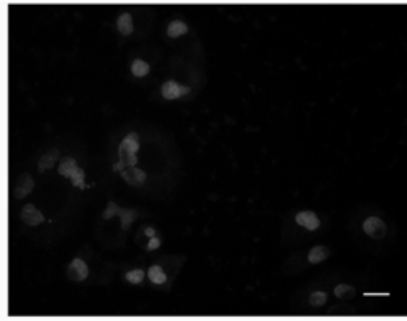

$8 \mu \mathrm{mol} / 1$

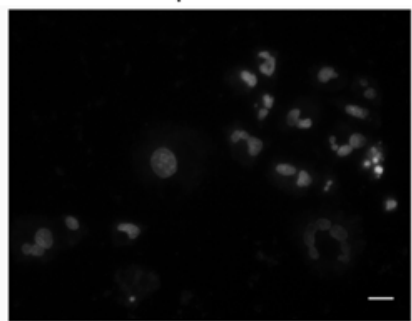

C

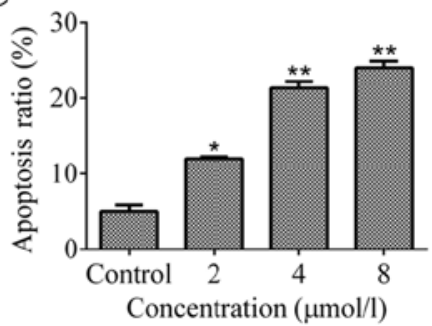

Figure 3. TPD7 induces apoptosis of cervical cancer HeLa cells. (A) Images of Hoechst 33258-stained HeLa cells after treatment with TPD7 for 48 h. Representative images of three independent experiments are shown. Scale bars, $10 \mu \mathrm{m}$. (B) Flow cytometric analysis of TPD7-induced apoptosis. Cells were incubated with TPD7 for $48 \mathrm{~h}$ and then stained with FITC-conjugated Annexin V and propidium iodide and analyzed with flow cytometry. (C) Quantification of the flow cytometric results in $\mathrm{B}$. Data are presented as the mean percentages of apoptosis $\pm \mathrm{SEM}$ for triplicate experiments. ${ }^{*} \mathrm{P}<0.05$; ${ }^{* *} \mathrm{P}<0.01$ compared with the control.

$\mathbf{A}$

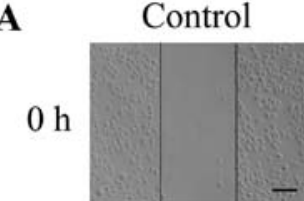

$2 \mu \mathrm{mol} / 1$

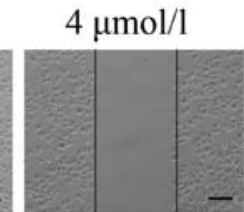

$8 \mu \mathrm{mol} / 1$
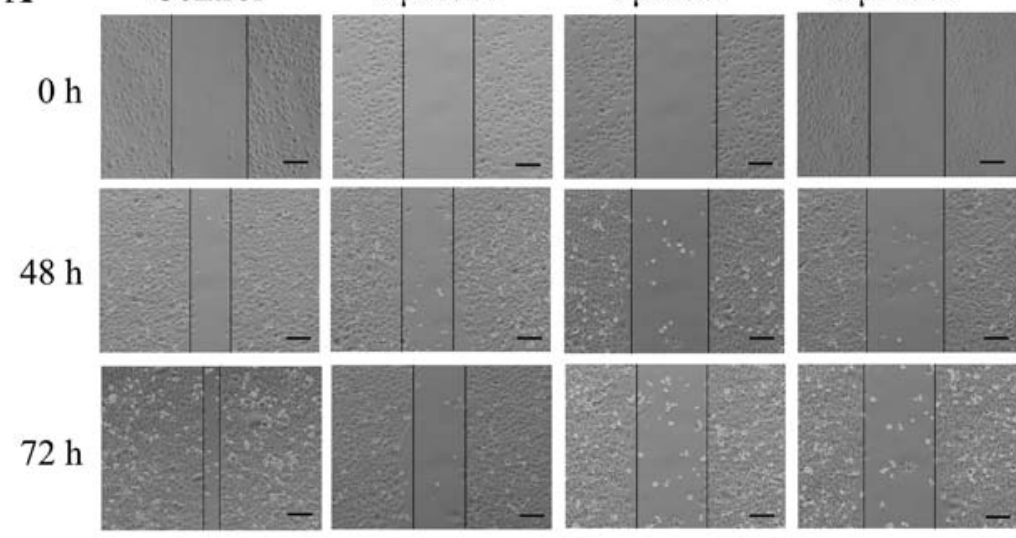

B
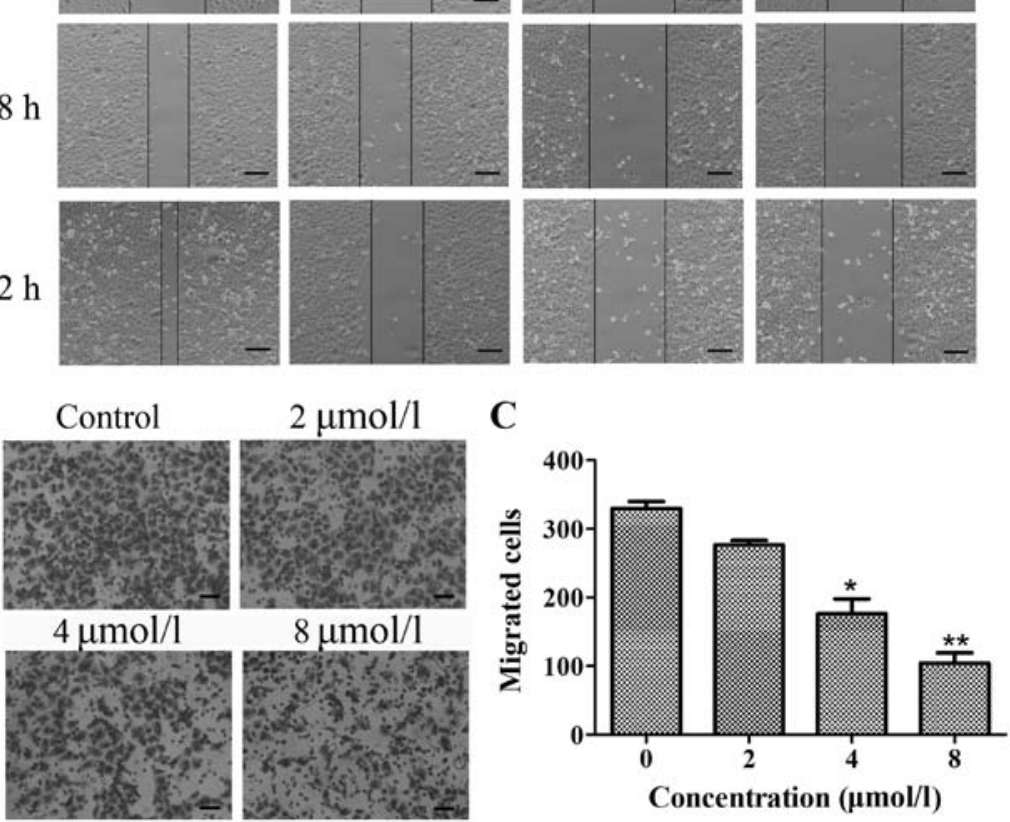

Figure 4. TPD7 suppresses the migration of HeLa cells. (A) Representative images of wounds on HeLa cell monolayers. Adherent cells were scratched and treated with TPD7 for 48 or $72 \mathrm{~h}$. The images reveal the same area at 0, 48 and $72 \mathrm{~h}$. Scale bars, $100 \mu \mathrm{m}$. (B) Representative images of HeLa cells migrating through an $8-\mu \mathrm{m}$ polycarbonate membrane. Scale bars, $40 \mu \mathrm{m}$. HeLa cells seeded into the chamber were treated with TPD7 for $48 \mathrm{~h}$. The cells were then fixed with $100 \%$ methanol and stained with $0.2 \%$ crystal violet for $15 \mathrm{~min}$. The cells on the upper chamber were removed, and the cells on the lower chamber (migrating cells) were photogaraphed under a microscope. (C) Quantification of migrating cells. Data are presented as the mean \pm SEM for triplicate experiments. ${ }^{*} \mathrm{P}<0.05 ;{ }^{* *} \mathrm{P}<0.01$ compared with control.

We also evaluated cancer cell invasion through Matrigelcoated chambers. As shown in Fig. 5, a similar effect of TPD7 on invasiveness was also observed in this system. These results indicated that TPD7 has anticancer properties that can significantly suppress cell invasion in a concentration-dependent manner. 

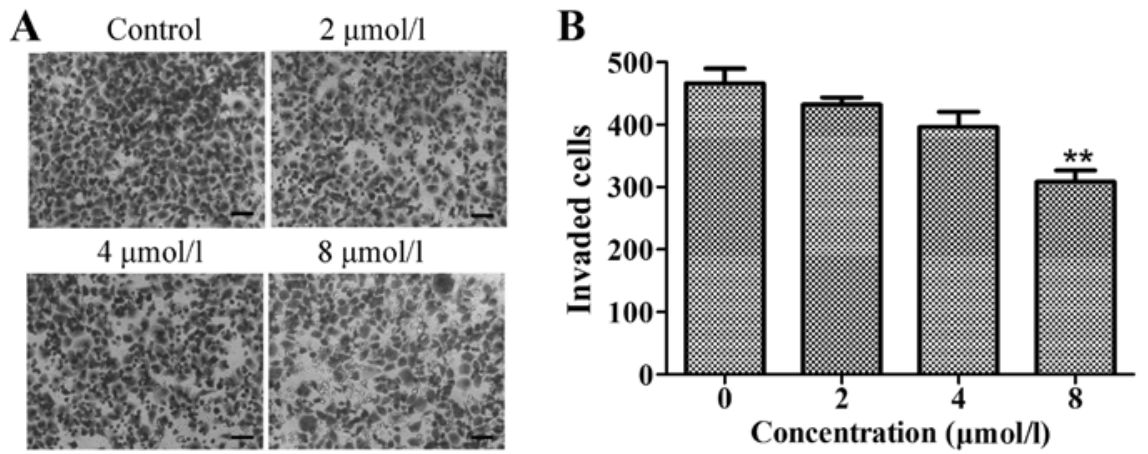

Figure 5. TPD7 inhibits HeLa cell invasion. (A) Representative images of cell invasion through Matrigel-coated polycarbonate membranes. Scale bars, $40 \mu \mathrm{m}$. Cells passing through the Matrigel-coated membrane were fixed with $100 \%$ methanol and stained with $0.2 \%$ crystal violet, and photographed under a microscope. (B) Quantification of invading cells. The results displayed are representative of three independent experiments. Data are presented as the means \pm SEM. ${ }^{* *} \mathrm{P}<0.01$ compared with the control cells.
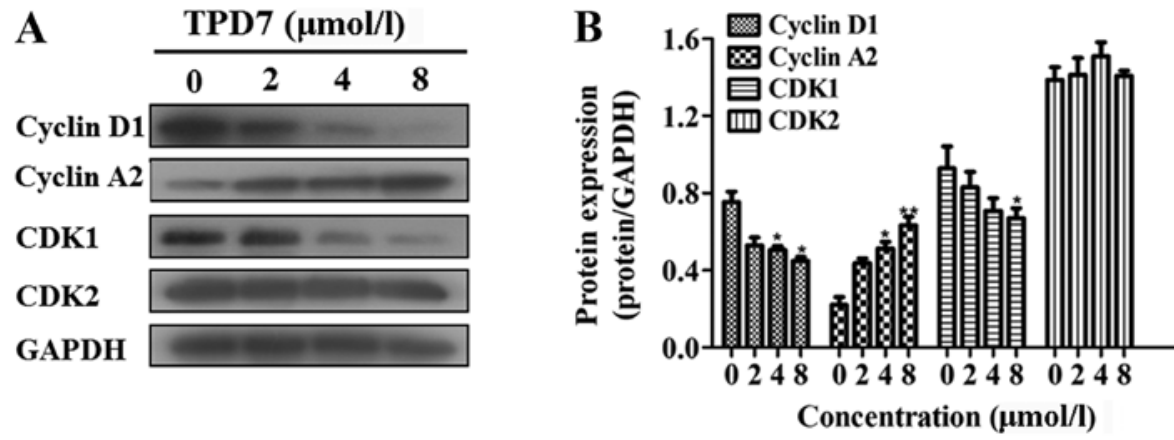

Figure 6. TPD7 regulates the expression of proteins involved in the cell cycle. (A) HeLa cells were treated with TPD7 for $48 \mathrm{~h}$. The cells were then lysed and the protein extract was analyzed by western blotting for cyclin D1, cyclin A2, CDK1 and CDK2. GAPDH was used as an internal control. Representative blots of triplicate experiments are shown. (B) Quantitative data are presented as the means \pm SEM. ${ }^{*} \mathrm{P}<0.05,{ }^{* * *} \mathrm{P}<0.01$ compared with the control.

Table I. Effect of treatment with TPD7 in nude mice bearing HeLa human cervical cancer xenografts.

\begin{tabular}{lcccccc}
\hline Treatment & $\begin{array}{c}\text { Initial body } \\
\text { weight }(\mathrm{g})\end{array}$ & $\begin{array}{c}\text { Initial tumor } \\
\text { volume }\left(\mathrm{cm}^{3}\right)\end{array}$ & $\begin{array}{c}\text { Final body } \\
\text { weight }(\mathrm{g})\end{array}$ & $\begin{array}{c}\text { Final tumor } \\
\text { volume }\left(\mathrm{cm}^{3}\right)\end{array}$ & $\begin{array}{c}\text { Final tumor } \\
\text { weight }(\mathrm{g})\end{array}$ & $\begin{array}{r}\text { Tumor growth } \\
\text { inhibition }(\%)\end{array}$ \\
\hline Control & $18.85 \pm 1.31$ & $0.108 \pm 0.02$ & $17.68 \pm 0.97$ & $1.95 \pm 0.12$ & $0.74 \pm 0.14$ & - \\
TPD7 & & & & & & \\
$(50 \mathrm{mg} / \mathrm{kg})$ & $19.95 \pm 1.17$ & $0.107 \pm 0.02$ & $18.55 \pm 1.35$ & $1.75 \pm 0.33$ & $0.68 \pm 0.16$ & 8.37 \\
$(100 \mathrm{mg} / \mathrm{kg})$ & $19.55 \pm 2.09$ & $0.104 \pm 0.01$ & $19.00 \pm 2.21$ & $1.32 \pm 0.26^{\mathrm{a}}$ & $0.53 \pm 0.28^{\mathrm{a}}$ & 28.73 \\
$(200 \mathrm{mg} / \mathrm{kg})$ & $19.53 \pm 1.73$ & $0.110 \pm 0.03$ & $17.33 \pm 2.22$ & $0.88 \pm 0.31^{\mathrm{b}}$ & $0.36 \pm 0.20^{\mathrm{b}}$ & 51.58 \\
\hline
\end{tabular}

Values are expressed as the mean \pm standard error of the mean $(\mathrm{SEM}) .{ }^{\mathrm{a}} \mathrm{P}<0.05,{ }^{\mathrm{b}} \mathrm{P}<0.01$ vs. the control.

TPD7 alters the expression of proteins related to the cell cycle and apoptosis. Multiple signal transduction pathways take part in regulating the cell cycle distribution, apoptosis, and cell invasion. Since TPD7 treatment induced S-phase arrest in HeLa cells, we evaluated the expression of proteins regulating the cell cycle. Treatment with TPD7 for $48 \mathrm{~h}$ led to a significant increase in cyclin A2, and a subsequent decrease in cyclin D1 and CDK1 protein expression. There was no change in CDK2 expression (Fig. 6).

Next, we examined the expression of proteins related to apoptosis including Fas receptor signaling and Bcl-2 family proteins in HeLa cells. TPD7 treatment upregulated Apaf-1, Bax and Bad and significantly downregulated Bcl-2 Mcl-1 and
NF- $\kappa B$ p65 protein levels. In addition, TPD7 upregulated the expression of Fas, FADD, cleaved caspase-3, cleaved PARP and p53 (Fig. 7A-E).

MMP-2, MMP-9 and CXCR4 are key molecules in the processes of cancer cell invasion and metastasis. The potential effect of TPD7 treatment on the expression of these proteins in HeLa cells was investigated. HeLa cells treated with TPD7 exhibited significant inhibitory effects on MMP-9 and CXCR4 expression, but no effect on MMP-2 (Fig. 8).

TPD7 is efficacious against HeLa cell xenograft tumors in vivo. A mouse model was used to evaluate the ability of TPD7 to suppress tumor growth in vivo. Prior to xenograft 
A

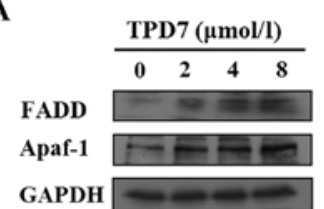

B

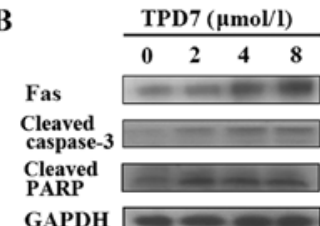

C

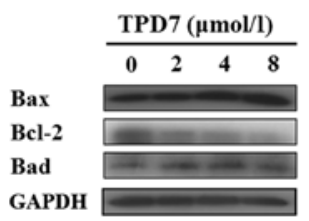

D

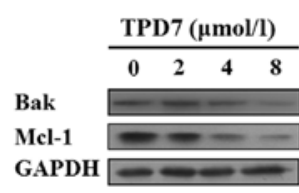

$\mathbf{E}$
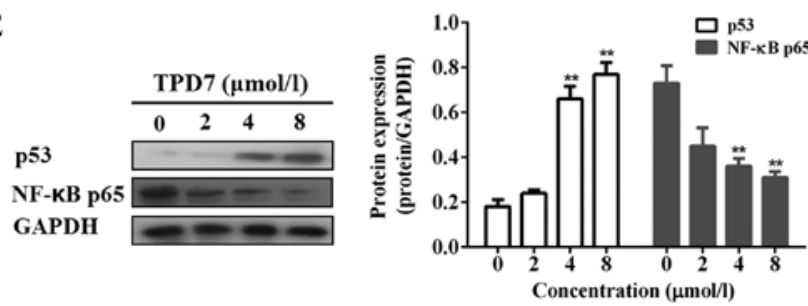

Figure 7. TPD7 modulates the expression of intrinsic and extrinsic apoptosis pathway proteins. (A) Western blots of FADD and Apaf-1 proteins. (B) Western blots of Fas, cleaved caspase-3 and cleaved PARP proteins. (C) Western blots of Bax, Bcl-2 and Bad proteins. (D) Western blots of Bak and Mcl-1 proteins. (E) Western blots of $\mathrm{p} 53$ and NF-kB p65 proteins GAPDH was used as an internal control. Representative blots of triplicate experiments are shown. Data are presented as the means \pm SEM. ${ }^{*} \mathrm{P}<0.05$, ${ }^{* *} \mathrm{P}<0.01$ compared with the control.

studies, we determined toxicity of TPD7 in mice by acute toxicity test. Receiving TPD7 at a dosage of $1,000 \mathrm{mg} / \mathrm{kg}$ did not lead to toxic effects in mice, and the TPD7 dose toxic to $10 \%$ of the animals (LD10) was $2,000 \mathrm{mg} / \mathrm{kg}$, therefore, one-tenth of the LD10, $200 \mathrm{mg} / \mathrm{kg}$, was considered to be a safe dose, and was used as the maximum tested dose in the xenograft studies. The medium tested dose and the minimum tested dose were 100 and $50 \mathrm{mg} / \mathrm{kg}$, respectively. Table I revealed the tumor growth in animals treated with vehicle or TPD7. TPD7 significantly decreased tumor weight in HeLa cell xenografted athymic mice compared with vehicle-treated animals. Furthermore, mice receiving TPD7 had no evident
A

\begin{tabular}{|c|c|c|c|c|}
\hline & \multicolumn{4}{|c|}{ TPD7 $(\mu \mathrm{mol} / \mathrm{l})$} \\
\hline & 0 & 2 & 4 & 8 \\
\hline MMP-2 & & 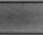 & & \\
\hline MMP-9 & - & $=$ & $=$ & \\
\hline CXCR4 & $\square$ & $=$ & $=$ & \\
\hline GAPDH & & & & \\
\hline
\end{tabular}

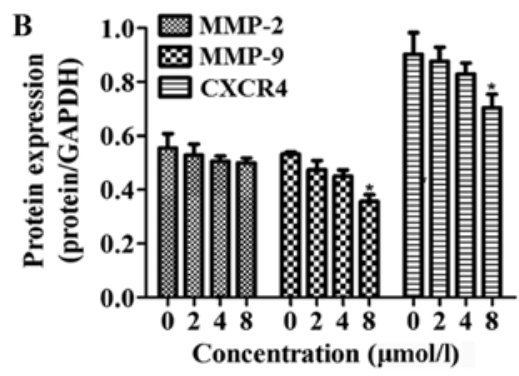

Figure 8. TPD7 decreases the expression of proteins mediating cell invasion. (A) Western blots of MMP-2, MMP-9 and CXCR4 in HeLa cells. (B) Quantification of the data in A. GAPDH was used as an internal control Representative blots of triplicate experiments are shown. Data are presented as the means \pm SEM. ${ }^{*} \mathrm{P}<0.05$ compared with the control.

loss of body weight during the experiment, suggesting that TPD7 was nontoxic in athymic mice at the dose used.

\section{Discussion}

Despite the increasing number of novel anticancer drugs being applied clinically to treat cancer, the development of acquired resistance ultimately limits the use of these agents. Thus, novel therapeutic strategies targeting cancer cells are urgently needed. The induction of apoptosis in cancer cells has revealed promising antitumor effects in many cancer models. Apoptosis is a normal physiological process that functions to orderly maintain the balance of cell numbers in multicellular organisms. However, when the balance is disrupted, human cancers may occur $(7,17)$.

Our research focused on identifying novel taspine derivatives that exhibit anticancer activity in HeLa cells. We previously revealed tumor inhibitory effects in breast cancer (18). In the present study, TPD7 decreased the viability and arrested the cell cycle of HeLa cells. We hypothesized that TPD7 treatment induced apoptosis and thereby inhibited cell proliferation. Apoptosis was assessed in TPD7-treated HeLa cells and we determined that TPD7 induced this form of cell death.

Cell cycle dysregulation may result in the uncontrolled proliferation that underlies the malignant phenotype (19). Therefore, blockade of cell cycle progression is regarded as a useful approach to shrink or kill tumors. Progression through the cell cycle is also tightly controlled by CDKs 1-6, whose activity requires association with specific cyclin subunits (20). G1 progression and the transition between the $\mathrm{G} 1$ and $\mathrm{S}$ phases requires depletion in cyclin $\mathrm{D}$, while CDK2 controls the $\mathrm{S}$ phase when associated with cyclin A (21-23). In this study, we demonstrated that TPD7 induced S-phase blockade in HeLa cells, resulting in a corresponding reduction of cells in both the G1 and G2/M phases. Downregulation of cyclin D1 and CDK1, and upregulation of cyclin A2 after TPD7 treatment was subsequent to the $\mathrm{G} 1 / \mathrm{S}$ phase transition and followed by a reduction of cells in the $\mathrm{G} 2 / \mathrm{M}$ phase. 
To ascertain TPD7-induced cell apoptosis in HeLa cells, we determined the presence of apoptotic cells following TPD7 treatment. As predicted, more apoptotic cells could be observed in TPD7 treatment groups by Hoechst staining. Additional verification for TPD7-triggered HeLa cell apoptosis involved FITC-labeled Annexin V/PI staining and flow cytometry. HeLa cells exposed to TPD7 exhibited increases in both early and late apoptotic cells.

Apoptosis can be triggered through two key molecular signaling pathways. One is the death receptor (Fas/FasL) pathway, known as the extrinsic apoptosis pathway. This pathway is initiated when death receptors on the cell surface interact with specialized ligands and is closely related to tumor progression (24). Fas-associated protein death domain (FADD) is a protein that plays a crucial role in the apoptotic pathway of Fas. It recruits procaspase- 8 to promote formation of the death-inducing signaling complex (DISC) and mediates receptor-induced apoptosis (25). The intrinsic apoptosis pathway is another signaling system involved in this form of cell death. This pathway can be triggered by members of the Bcl-2 family of proteins and downstream mitochondrial signals $(6,26,27)$. Both pathways converge to activate caspases, which are the final step carrying out numerous proteolytic events that mediate the apoptotic program (28). Among the caspases, caspase- 3 is a crucial protease activated by death signals to hydrolyze many key specific substrates (29). In this study, Fas, FADD, caspase-3, and the cleavage of PARP were upregulated in HeLa cells treated with TPD7.

Pro- and anti-death proteins of the Bcl-2 family are the major molecules involved in the intrinsic apoptosis pathway (30). Mcl-1, Bcl-2, Bcl-XL and Bcl-W function as anti-apoptotic molecules, and their expression can be elevated in many tumors. Bax, Bak and Bad, identified as cell-death mediators of the Bcl-2 family, accelerate apoptosis induced by external stimuli (31). We detected the key Bcl-2 family molecules involved in apoptosis and found that the pro-apoptotic proteins, such as Bad and Bax, were upregulated in TPD7treated cells. In contrast, the anti-apoptotic proteins, Mcl-1 and Bcl-2, were downregulated in TPD7-treated cells. Apaf-1, a cell-death effector, functions downstream of Bcl-2 but upstream of caspase-3. It binds to cytochrome $\mathrm{c}$ to trigger the activation of caspase-3, leading to apoptosis (32). The amount of Apaf-1 protein was markedly increased by TPD7 treatment Restoring physiological levels of Apaf-1 by TPD7 may contribute to enhance sensitivity to apoptosis signals.

p53 serves as a tumor suppressor that affects the progression of apoptosis primarily through modulating key functional proteins in the intrinsic pathway. The pro-apoptotic activity of p53 occurs by directly activating the transcription of genes that initiate the apoptotic program (33). TPD7 upregulated the expression of p53 in HeLa cells and, accordingly, promoted apoptosis thereby decreasing HeLa cell viability and proliferation.

To characterize the in vivo inhibitory activity of TPD7 on cancer, we conducted studies using xenograft tumors in mice. We consistently observed an inhibition of tumor growth in TPD7-treated mice, suggesting that TPD7 may be a good candidate for cervical cancer intervention.

In conclusion, our findings revealed that TPD7-mediated cell cycle arrest was associated with downregulation of cyclin D1 and CDK1, along with an increase of cyclin A2. Furthermore,
TPD7-induced apoptosis in cervical cancer cells was mediated through both the intrinsic and extrinsic pathways. These findings demonstrated that TPD7, a novel taspine derivative, is a potential agent against cervical carcinoma in vitro and in vivo.

\section{Acknowledgements}

Not applicable.

\section{Funding}

The present study was supported by the National Natural Science Foundation of China (grant nos. 81302800 and 81773772), the Natural Science Basic Research Plan of Shaanxi Province in China (grant no.2015JQ8296) and the Basic Research Project in Shaanxi Administration of Traditional Chinese Medicine (grant no. JCMS028).

\section{Availability of data and materials}

The datasets used during the present study are available from the corresponding author upon reasonable request.

\section{Authors' contributions}

YiZ, YaZ and LH conceived and designed the study. YiZ, HZ, $\mathrm{BD}$ and $\mathrm{JZ}$ contributed to the acquisition of the data. YiZ, YaZ, JZ and LH wrote, reviewed and revised the manuscript. LH supervised the study. All authors read and approved the manuscript and agree to be accountable for all aspects of the research in ensuring that the accuracy or integrity of any part of the work are appropriately investigated and resolved.

\section{Ethics approval and consent to participate}

The use of Balb/c mice for the purpose of this study was approved by the Animal Ethics Committee of Xi'an Jiaotong University (Permission no. XJTULAC2013-031). All experiments were conducted in accordance with the approved guidelines of the regional authorities according to Xi'an Jiaotong University animal care regulations.

\section{Patient consent for publication}

Not applicable.

\section{Competing interests}

The authors declare that they have no competing interests.

\section{References}

1. Wright AA, Howitt BE, Myers AP, Dahlberg SE, Palescandolo E, Van Hummelen P, MacConaill LE, Shoni M, Wagle N, Jones RT, et al: Oncogenic mutations in cervical cancer: Genomic differences between adenocarcinomas and squamous cell carcinomas of the cervix. Cancer 119: 3776-3783, 2013.

2. Siegel RL, Miller KD and Jemal A: Cancer statistics, 2016. CA Cancer J Clin 66: 7-30, 2016.

3. Koh WJ, Greer BE, Abu-Rustum NR, Apte SM, Campos SM, Chan J, Cho KR, Cohn D, Crispens MA, DuPont N, et al; National Comprehensive Cancer Network: Cervical cancer. J Natl Compr Canc Netw 11: 320-343, 2013. 
4. Torre LA, Siegel RL, Ward EM and Jemal A: Global cancer incidence and mortality rates and trends - An update. Cancer Epidemiol Biomarkers Prev 25: 16-27, 2016.

5. Siegel RL, Fedewa SA, Miller KD, Goding-Sauer A, Pinheiro PS, Martinez-Tyson D and Jemal A: Cancer statistics for Hispanics Latinos, 2015. CA Cancer J Clin 65: 457-480, 2015.

6. Fulda S and Debatin KM: Extrinsic versus intrinsic apoptosis pathways in anticancer chemotherapy. Oncogene 25: 4798-4811, 2006.

7. Hengartner MO: The biochemistry of apoptosis. Nature 407 : 770-776, 2000

8. Fulda S and Debatin KM: Sensitization for anticancer druginduced apoptosis by the chemopreventive agent resveratrol. Oncogene 23: 6702-6711, 2004.

9. Green DR and Kroemer G: The pathophysiology of mitochondrial cell death. Science 305: 626-629, 2004.

10. Ashkenazi A: Targeting death and decoy receptors of the tumournecrosis factor superfamily. Nat Rev Cancer 2: 420-430, 2002

11. Chen J, Solomides C, Parekh H, Simpkins F and Simpkins H: Cisplatin resistance in human cervical, ovarian and lung cancer cells. Cancer Chemother Pharmacol 75: 1217-1227, 2015.

12. Shen Y, Wang P, Li Y, Ye F, Wang F, Wan X, Cheng X, Lu W and $\mathrm{Xie} \mathrm{X}$ : miR-375 is upregulated in acquired paclitaxel resistance in cervical cancer. Br J Cancer 109: 92-99, 2013

13. Wang C, Dong J, Zhang Y, Wang F, Gao H, Li P, Wang S and Zhang J: Design, synthesis and biological evaluation of biphenyl urea derivatives as novel VEGFR-2 inhibitors. Bioorg Med Chem 4: 1434-1438, 2013

14. Li Y and He L: Establishment of the model of vascular endothelial cell membrane chromatography and its preliminary application. Chin Sci Bull 52: 922-928, 2007.

15. Zhan Y, Zhang Y, Chen Y, Wang N, Zheng L and He L: Activity of taspine isolated from Radix et Rhizoma Leonticis against estrogen-receptor-positive breast cancer. Fitoterapia 82: 896-902, 2011.

16. Zhang Y, He L, Meng L and Luo W: Taspine isolated from Radix et Rhizoma Leonticis inhibits proliferation and migration of endothelial cells as well as chicken chorioallantoic membrane neovascularisation. Vascul Pharmacol 48: 129-137, 2008.

17. Evan GI and Vousden KH: Proliferation, cell cycle and apoptosis in cancer. Nature 411: 342-348, 2001.

18. Zhan Y, Zhang H, Li J, Zhang Y, Zhang J and He L: A novel biphenyl urea derivate inhibits the invasion of breast cancer through the modulation of CXCR4. J Cell Mol Med 19: 1614-1623, 2015 .
19. Williams GH and Stoeber K: The cell cycle and cancer. J Pathol 226: 352-364, 2012.

20. Malumbres M, Harlow E, Hunt T, Hunter T, Lahti JM, Manning G, Morgan DO, Tsai LH and Wolgemuth DJ: Cyclin-dependent kinases: A family portrait. Nat Cell Biol 11: 1275-1276, 2009.

21. Diaz-Moralli S, Tarrado-Castellarnau M, Miranda A and Cascante M: Targeting cell cycle regulation in cancer therapy. Pharmacol Ther 138: 255-271, 2013.

22. Casagrande F and Darbon JM: Effects of structurally related flavonoids on cell cycle progression of human melanoma cells: Regulation of cyclin-dependent kinases CDK2 and CDK1. Biochem Pharmacol 61: 1205-1215, 2001.

23. Pagano M, Pepperkok R, Verde F, Ansorge W and Draetta G: Cyclin $\mathrm{A}$ is required at two points in the human cell cycle. EMBO J 11: 961-971, 1992.

24. Houston A and O'Connell J: The Fas signalling pathway and its role in the pathogenesis of cancer. Curr Opin Pharmacol 4: 321-326, 2004.

25. Lee EW, Kim JH, Ahn YH, Seo J, Ko A, Jeong M, Kim SJ, Ro JY, Park KM, Lee HW, et al: Ubiquitination and degradation of the FADD adaptor protein regulate death receptor-mediated apoptosis and necroptosis. Nat Commun 3: 978, 2012.

26. Kaufmann SH and Earnshaw WC: Induction of apoptosis by cancer chemotherapy. Exp Cell Res 256: 42-49, 2000.

27. Ghobrial IM, Witzig TE and Adjei AA: Targeting apoptosis pathways in cancer therapy. CA Cancer J Clin 55: 178-194, 2005.

28. Ashkenazi A: Targeting the extrinsic apoptosis pathway in cancer. Cytokine Growth Factor Rev 19: 325-331, 2008

29. Porter AG and Jänicke RU: Emerging roles of caspase-3 in apoptosis. Cell Death Differ 6: 99-104, 1999.

30. Tsujimoto Y: Cell death regulation by the Bcl-2 protein family in the mitochondria. J Cell Physiol 195: 158-167, 2003.

31. Hunter AM, LaCasse EC and Korneluk RG: The inhibitors of apoptosis (IAPs) as cancer targets. Apoptosis 12: 1543-1568, 2007.

32. Zou H, Henzel WJ, Liu X, Lutschg A and Wang X: Apaf-1, a human protein homologous to $C$. elegans $\mathrm{CED}-4$, participates in cytochrome c-dependent activation of caspase-3. Cell 90: 405-413, 1997

33. Fridman JS and Lowe SW: Control of apoptosis by p53. Oncogene 22: 9030-9040, 2003. 